\title{
Comparative Analysis Of Online Recruitment And Managerial Capabilities
}

\author{
Roblyn Simeon, (E-mail: rsimeon@sfsu.edu), San Francisco State University
}

\begin{abstract}
On-line recruitment is a phenomenon that is not only changing the traditional approach to human resource management but is also having a significant impact on other business strategies. Managerial recruitment appears to be the area having the greatest influence on business strategy. We examined two theoretical perspectives that help to explain the importance in the U.S. of aggressive screening and competence matching as firms seek out exceptional managerial candidates. We then used data collected from web sites to compare online managerial recruitment in Japan, the U.K., and the U.S. Due to cultural and institutional differences, we found that there were significant differences in a number of on-line recruitment strategies.
\end{abstract}

\section{Introduction}

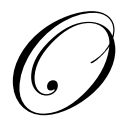

nline recruitment is a phenomenon that is not only changing the traditional approach to human resource management but is also having a significant impact on other business strategies. It is another aspect of the Internet revolution that is transforming the internal structures, processes and capabilities of many firms (Bell and Sutton 1998; Freeman 1999; Day Mar 2000). The benefits of recruiting online are many and firms are increasingly incorporating them into their business models.

In many sectors where the rapid acquisition of skills and talent is crucial for maintaining competitiveness, the ability to quickly find qualified candidates online can bolster firm performance. In addition to allowing firms to pre-screen potential applicants, it is now possible for organizations to expand their targeting of specific labor pools, regions, and professions. The effective use of online recruitment can lead to tremendous cost savings and strategic flexibility for both large and small firms (Casper 1985; Greengard 1995; Hildebrand 1998).

Separate from the benefits to corporations, online recruiting has changed the approach of individuals toward job search activities. Students, new graduates, mid-career workers, and the unemployed can actively seek out opportunities in locations far beyond their local geographic boundaries. There is even the opportunity for individuals to place their resumes online and actively market their skills, capabilities, and experience. All of these factors have accelerated the explosion in the amount of web sites with open position advertisements (Kay 2000; Martinez Aug 2000; Rudich Mar/Apr 2000).

Of the all the various aspects of on-line recruitment, the area that appears to be having the greatest influence on business strategy is managerial recruitment. This is due to the role of managers in developing, coordinating, and maintaining operational and strategic capabilities in a firm. Top and mid-level executives affect the hiring, training, and deployment of the bulk of employees in most firms. Their decisions can impact the organizational culture and strategy implementation. This is especially true in the U.S. where a premium is placed on leadership skills, extensive experience, and quick improvement in performance outcomes (Rawls 1974; Rosow 1990; Mercer 1993). However, one could argue that due to cultural and institutional differences, we might expect significant variation in online recruitment practices across national boundaries. (Worledge 1992; Campbell 1994; Welch 1999)

Readers with comments or questions are encouraged to contact the author via email.

In order to gain a better understanding of the online recruitment phenomenon, we will examine two theoret- 
ical perspectives that help to explain the importance in the U.S. of aggressive screening and competence matching as firms intensively search for exceptional managerial candidates. We will then compare online managerial recruitment in three different countries to ascertain whether or not the same tendencies and strategies dominate. This empirical investigation will be based mainly on data gathered from company web sites (position advertisements) in the U.S., Japan, and the U.K.

\section{Strategic Views and Online Recruitment}

Both the content and process of on-line managerial recruitment activities are heavily influenced by the competitive strategy and managerial style which dominates the company and business environment (Roberts, Kossek et al. 1998; Simonsen and Davidson 1999; Walker, Reif et al. 1999). The two theoretical perspectives which capture the major tendencies in recruitment strategies in the U.S. are (a) performance and behavioral screening and (b) resource and knowledge management. These two approaches directly or indirectly help to explain the behavioral and competence preferences of American firms.

\section{Performance and Behavioral Screening}

The emphasis in this approach is on profile tests which select for desired behaviors and skills while screening out unwanted attitudes (Hoffman 1996; Meger 1996; Starcke 1996). The assumption is that hiring is a complex process and a variety of techniques must be used to capture potential employees' pattern of behavior, strengths, and weaknesses. Behavioral interviewing, employee profiling, job analysis, and realistic job previews are some of the techniques which have been used by human resources departments to systematically screen and match managerial candidates to important positions. (Bretz and Judge 1998; Jiang, Klein et al. 1998; Phillips 1998; Robinson 1998). These and other studies have shown that effective screening can reduce employee turnover, identify critical behaviors and skills needed for success, and find individuals that fit the corporate culture (Dean and Wanous 1984; Green 1991; Buckley, Fedor et al. 1998; Hom, Griffeth et al. 1998).

\section{Resource and Knowledge Management}

This perspective focuses on the need for companies in today's competitive markets to quickly acquire competent, skilled, and adaptable managers. Competence development and matching are important aspects of this approach (Neumann 1988; Rollins 1989; Bice 1990; Meger 1996). Firms often examine star performers, key players, and experts to develop success profiles. The main assumption is that today's scare resources are information, knowledge, and expertise. The challenge for firms and countries is finding effective ways to attract, motivate and use the talents of these knowledge workers (Birkett 1995; Pitt and Clarke 1999; Lewin and Regine Sep/Oct 2000). Consequently, a company's recruiting practice becomes the foundation for its competitive advantage. This strategic perspective consistently highlights three objectives: (a) the search to fill knowledge gaps (b) the selection of top performers and (c) a focus on managerial positions. (Grinnell and Kochanek 1976; Neumann 1988; Greengard 1995).

\section{Empirical Context and Analytical Framework}

Apart from the benefit of lower costs, the Internet is transforming the entire recruitment process. This includes promotional activities, candidate identification and tracking, communication and screening, and finally selection and preparation of new staff (Appleton 1995; Bell and Sutton 1998; Bigelow 1999). Using web-site design, profile tests, and explicitly worded employment position statements, American firms have recreated the screening and recruitment processes online. Electronic resumes are easier to screen, sort, and store. Employee searches can take place in a variety of languages and across many different geographic areas. The Internet appears to offer an excellent solution for firms hoping to find qualified and effective candidates on short notice.

What the main recruitment perspectives above all have in common is the emphasis on screening out certain behaviors and attitudes while attracting individuals with the desired set of core traits, skills, and capabilities. The framework below (figure 1) incorporates the theoretical perspectives and reflects our view of the link between desired core performance factors and the stress placed on acquiring high impact managers. This framework served as 
the central analytical tool in this paper.

Figure 1: Strategic Focus of On-line Recruitment

Core Performance

High Impact Candidate

Attributes

(Managers)

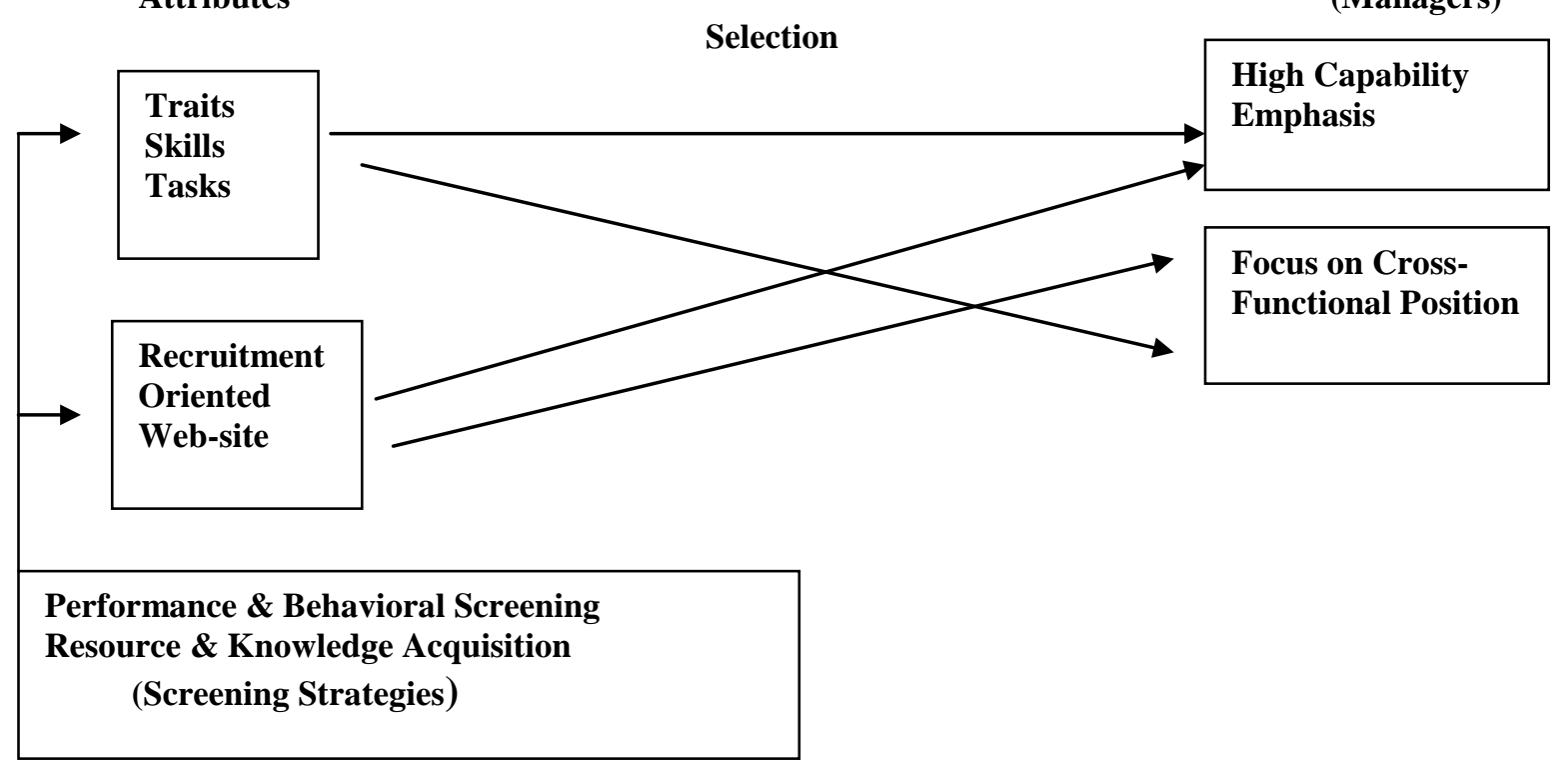

Performance \& Behavioral Screening Resource \& Competence Acquisition

Supporting the implications of this framework is the fact that as business competition intensifies on both the domestic and international fronts, companies are demanding more of their top level managers. Firms aggressively seek to acquire high impact supervisory staff who have an extensive set of capabilities. These high capability managerial candidates are those who can have an immediate impact on the firm's operations, profitability, and strategy.

Hypothesis I: The greater the screening emphasis on core traits, skills, and job tasks, the more likely it will be that the firm is seeking high impact managers.

Hypothesis II: The more extensive the recruitment orientation of a company's web site, the more likely will it be seeking high impact managers.

In order to compare online recruitment in three different countries, we decided to focus on information that can be directly gathered and evaluated from web-site design and employment position announcements. A number of researchers have shown how web site information can provide significant clues to understanding the strategy and corporate culture of business organizations (Urgo 1997; Simeon 1999; Tweney 1999). Using the analytical framework presented earlier, we examined web sites and employment announcements in the U.S., the U.K, and Japan.

\section{Data and Methodology}

The unit of analysis and main focus of the data collection was the employment position advertisement of firms in each country. The language of the web site announcements was analyzed and coded to capture the major concepts presented in the evaluation framework (figure 1). Similar strategies used to map the core performance and capabilities concepts have been used by other researchers (Huff 1990; Markham, Mintzes et al. 1994; Kolb and Shepherd 1997; Simeon 1999). 
Using our framework, basic information was collected on core performance factors, the recruitment orientation of the web sites and general job related restrictions. Table 1 shows an overview of the coding measures and data collected from the web sites in the U.S., U.K, and Japan. Data was collected from 551 position advertisements. All the positions advertised were located directly on the companies' web sites and were for middle and upper level managers. None of the positions were for engineers or computer programmers. Employment agencies and job search sites were not used. We consider the direct listings to be more indicative of the firms' recruitment strategy. Regression analysis was used to examine how well the desired core performance factors predicted the emphasis on high impact managers.

\section{Dependent Variables}

Two dependent variables were created to capture the concept of the high impact executive.

High managerial capability was the sum total of nine desired managerial capabilities listed $(0,1$ measures) on the position advertisement (table 1). The capabilities include the ability to lead, boost revenues, manage teams, and motivate staff, market services and set strategy. For cross functional focus, an independent evaluator graded the advertised position on a 1-5 scale for the extent to which it required some knowledge of the service, marketing, technical, or strategic functions (table 1). The combined score reflects the level of cross-functional emphasis.

\section{Table 1: Overview of Data Collected from Websites and Coding Approach}

\author{
Web Site Orientation $(0=$ no, $1=$ yes $)$ \\ 1. company background info. online \\ 2. can submit resume online \\ 3. many different jobs listed online \\ 4. job openings listed by departments \\ 5. job opening listed by function \\ 6. job opening listed by location
}

\section{Internal job performance conditions}

\section{A. Core Skills $(0=n o, 1=y e s)$}

1. have communication skills

2. have writing skills

3. knows standard software

4. basic internet skills

5. knows a foreign language

B. Core Traits $(0=n o, 1=y e s)$

1.should be creative

2. should be a self-learner

3 . be a good problem solver

4. should be dependable

5. should be flexible

6. should be innovative

C. Core Job Tasks ( $0=n o, 1=y e s)$

1.know how to process forms

2. produce reports

3. must do presentations

4. organize meetings

5. should update co. website

6 . research the market

7. interact with customers

8. work with co. sections.

\author{
External job conditions $(0=$ no, $1=y e s)$ \\ 1. age limits exist for the position \\ 2. gender preferences clearly indicated \\ 3. more than 1 year experience required \\ 4. college degree required for position \\ 5 . salary varies by experience \\ 6. salary varies by age \\ 7. position requires much traveling
}

Desired Core Managerial Capabilities (0,1)

1. Should be able to motivate staff

2. Should provide strong leadership

3. Should generate revenue increases

4. Should be able to manage teams

5. Should effectively market the firm's products

6. Should understand main human resource issues

7. Should know different business models

8. Should be able to set departmental strategy

9. Should understand/set company strategy

Multi-Function Orientation of Job (1-5 scale)

Evaluator indicated on a scale from 1-5 (high), the extent to which the position had the following characteristics:
A. Service
B. Marketing
C. Technical
D. Strategic

\section{Independent Variables}

Recruitment oriented web-site was the total of six design features of the web site that facilitated the gathering of information about the company and the possibility of applying on-line for the positions (table 1). Core per- 
formance skills emphasis was the total of five desired skills for position (table 1). The core skills that we compared across firms include communication, writing, Internet, software, and foreign language abilities. Core traits emphasis was the total of six desired traits for prospective managers (table 1). The main core traits compared were creativity, flexibility, innovation, and a problem-solving orientation. Core job tasks emphasis was the total of eight required tasks for the positions (table 1). The core tasks included doing reports, presentations, market research, and web-site maintenance. American firms and British firms were dummy variables created with Japanese firms as the reference category. The significant outcomes would thus be a comparison to the level present in Japanese advertised positions.

\section{Results}

Although the goal of this paper is to show how the emphasis on certain core screening factors results in the strong focus on high impact managers, we also decided to clarify the differences between the three countries compared. We used ANOVA to test for significant differences in the means for the variables used. We can see from table 2 that significant differences exist between the U.S. and Japan as well as between the U.K. and Japan. On the other hand, for most of the variables, there were only minor differences between the U.S. and the U.K. Yet, for both recruitment orientation of web-site and the emphasis on high managerial capabilities, there were significant differences between the U.S. and the U.K. (table 2). In general, we also see that the standard deviations for Japan are smaller than those of the U.S. and the U.K. This indicates greater similarity among the Japanese firms in their online recruitment strategies.

Using regression analysis, we examined the impact of web design related and core performance factors on the dependent variables. The theoretical perspectives behind managerial recruitment strategies in the U.S. suggested an emphasis on screening for core traits and skills while clearly presenting the required job tasks. All of the independent variables except core skills had a significant impact on the emphasis on high managerial capabilities.

Table 2: Comparison of Means for 3 Countries (Anova)

\begin{tabular}{|c|c|c|c|c|c|c|}
\hline \multirow{3}{*}{ 1. External performance conditions } & U.S. & U.K. & U.S. & Japan & Japan & U.K. \\
\hline & $\overline{1.96}$ & $\overline{1.82}+$ & $\overline{1.96}$ & $2.19 *$ & 2.19 & $1.82 * *$ \\
\hline & $(.74)$ & $(1.04)$ & $(.74)$ & $(.98)$ & $(.98)$ & $(1.04)$ \\
\hline \multirow[t]{2}{*}{ 2. Human resource oriented web site } & 5.39 & $4.44 * * *$ & $3.92 * * *$ & & 3.92 & $4.44 * *$ \\
\hline & $(1.40)$ & $(1.64)$ & $(.82)$ & & $(.82)$ & $(1.64)$ \\
\hline \multirow[t]{2}{*}{ 3. Core performance skills } & 2.69 & $2.47+$ & 2.69 & $1.31 * * *$ & 1.31 & $2.47 * * *$ \\
\hline & $(1.35)$ & & $(1.03)$ & & $(1.35)$ & \\
\hline \multirow[t]{2}{*}{ 4. Core performance traits } & 3.17 & $3.00+$ & 3.17 & $.25 * * *$ & .25 & $3.00 * * *$ \\
\hline & $(2.08)$ & & $(.59)$ & & $(.59)$ & $(2.08)$ \\
\hline 5. Core performance job tasks & 3.59 & $3.37+$ & 3.59 & $1.11 * * *$ & 1.11 & $3.37 * * *$ \\
\hline \multirow{2}{*}{ 6. High managerial capabilities } & $\begin{array}{c}(1.88) \\
4.58\end{array}$ & $3.91 * * *$ & $\begin{array}{c}(1.08) \\
4.58\end{array}$ & $1.40 * * *$ & (1.88) & $3.91 * * *$ \\
\hline & $(2.36)$ & $(2.43)$ & $(2.36)$ & $(1.12)$ & $(2.43)$ & \\
\hline \multirow[t]{2}{*}{ 7. Multi-functional oriented position } & 16.08 & $15.62+$ & 16.08 & $1.40 * * *$ & 1.40 & $15.62 * * *$ \\
\hline & $(4.50)$ & $(4.27)$ & $(4.50)$ & $(1.12)$ & $(1.12)$ & $(4.27)$ \\
\hline (A) \# of position advertisements & 239 & 212 & 239 & 100 & 100 & 212 \\
\hline Means (standard deviations) $* \mathrm{p}<0.05$ & $* \mathrm{p}<0.01$ & $* * * \mathrm{p}<0.001$ & & & & \\
\hline
\end{tabular}

In line with our hypotheses, recruitment oriented web-sites and explicit emphasis on core traits and job tasks in position advertisements were good indicators that firms wanted exceptional managers (table 4). It is also clear that both American and British firms were much more likely to show these tendencies than Japanese firms. The adjusted R-square of .45 for this regression (model 1) indicates that these independent variables have significant explanatory power.

Another aspect of the high impact executive concept was the tendency for positions to have a crossfunctional focus. This dependent variable captures the idea that the desired managers should demonstrate the ability to solve a variety of marketing, service, technical and strategic problems. Core job tasks emphasis and recruitment oriented web sites were the variables that had a significant impact on this dependent variable (model 2). American and British firms were again more likely to stress these abilities in their position advertisements. These results pro- 
vide strong support for both hypotheses I \& II.

Table 3: Correlation Coefficients

1. HR Oriented site

2. Core performance skills

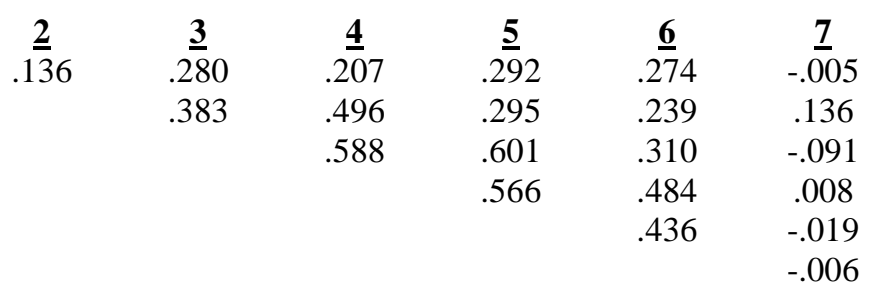

3. Core performance traits

4. Core job tasks

5. Core managerial capabilities

6. Cross-functional position

7. External performance conditions

Table 4: Regression High Managerial Capabilities Cross-functional Focus

\begin{tabular}{|c|c|c|}
\hline \multirow[b]{2}{*}{ 1. Recruitment oriented site } & \multicolumn{2}{|c|}{ Coefficient (se) } \\
\hline & .135 & $(.06)^{*}$ \\
\hline 2. Core performance skills & -.108 & $(.07)+$ \\
\hline 3. Core performance traits & .399 & $(.05)^{* * * *}$ \\
\hline 4. Core job tasks & .383 & $(.05)^{* * *}$ \\
\hline 5. American firms & 1.02 & $(.27) * * *$ \\
\hline 6. British firms & .603 & $(.26)^{*}$ \\
\hline Constant & & 86 \\
\hline Adjusted R-square & & 54 \\
\hline$N=\#$ of position advertisements & & 51 \\
\hline$* * \mathrm{p}<0.01$ & & \\
\hline
\end{tabular}

\begin{tabular}{ll}
\multicolumn{2}{r}{ Coefficient (se) } \\
.467 & $(.11)^{* * * *}$ \\
-.140 & $(.14)+$ \\
-.139 & $(.10)+$ \\
.916 & $(.11)^{* * * *}$ \\
& $(.55)^{* * *}$ \\
2.615 & $(.53)^{* * *}$ \\
& 8.60 \\
& .291 \\
& 551
\end{tabular}

A comparative view of the expected capabilities of managers indicates that the American firms require the widest range of capabilities (table 5). Managers should not only generate revenues but also be strong leaders with a good knowledge of company and market strategy. There was a clear range of expectations across the three countries. The Japanese firms were the least explicit about the performance expectations of its managers. Although the British and American firms had similar measures for many aspects of managerial capabilities, the overall difference was significant (table 5).

Table 5: Comparative View of Expected Managerial Capabilities Means (standard deviations)

\begin{tabular}{llll} 
Desired Managerial Capabilities & American & $\underline{\text { British }}$ & $\underline{\text { Japanese }}$ \\
\cline { 2 - 3 } 1. Be able to motivate staff & $.54(.50)$ & $.42(.50)$ & $.13(.34)$ \\
2. Provide strong leadership & $.67(.47)$ & $.58(.49)$ & $.18(.39)$ \\
3. Generate revenue increase & $.37(.48)$ & $.59(.49)$ & $.18(.39)$ \\
4. Manage teams well & $.58(.49)$ & $.39(.49)$ & $.12(.33)$ \\
5. Market the firm's products & $.45(.50)$ & $.22(.41)$ & $.24(.43)$ \\
6. Understand HR issues & $.34(.47)$ & $.55(.50)$ & $.04(.20)$ \\
7. Know business models & $.64(.49)$ & $.51(.50)$ & $.11(.33)$ \\
8. Set department strategy & $.65(.48)$ & $.31(.46)$ & $.23(.42$ \\
9. Understand/set co. strategy & $.34(.48)$ & &
\end{tabular}

\section{Conclusion}

The phenomenon of online recruitment can be examined from many perspectives. The statistics about the increasing usage worldwide of on-line recruitment strategy can tell an interesting story. A discussion of the growing variety of web tools and information technologies used to manage the recruitment process also provides insight into 
this phenomenon. However, the main interest of this paper has been about what on-line recruitment can tell us about the types of managers and business strategies that are the major preoccupation of firms in three different market environments.

The centerpiece of our investigation was the information presented on company web-sites about open managerial positions. Our review of the literature on recruitment strategy in the U.S. revealed an intense focus on job design, and the core performance capabilities of prospective employees. Our analytical framework (figure 1) posited that the desired skills, traits, and tasks would predict a preference for high impact executives. The regression analyses provided support for our hypotheses but also showed that significant differences existed across countries.

One aspect of on-line managerial recruitment that showed an interesting variation across countries was the extent to which there was an explicit stating of desired employee characteristics and expected performance outcomes. In the American environment, recruitment theories have supported the view that aggressive and explicit job descriptions and competence expectations result in the selection of more committed workers, lower turnover, and better performers (Dean and Wanous 1984; Suszko and Breaugh 1986; Buckley, Fedor et al. 1998). On the other hand, Japanese firms have relied more on relationship driven recruitment coupled with intense socialization around company expectations and culture (Campbell 1994). Their on-line description of desired characteristics were minimal (table 2). It appears that British firms have been more strongly influenced by the American recruitment models.

Another difference across countries which shows up clearly in the position advertisements is the intense drive by American firms to acquire high capability managers who can make an immediate impact on company performance. American firms not only explicitly state revenue generating targets for some managers but demand a wide range of capabilities and employment experiences. This is a reflection of the stress on transformational leadership and high profile managers (McBain 1998; Simonsen and Davidson 1999). Both the Japanese and British firms were much more moderate in their search for skilled managers.

Finally, American firms and British firms were acutely aware of the importance of attracting mobile knowledge executives for the most appropriate positions. Compared to Japan, there is clearly a much more active market in the U.S. and the U.K for job-hopping knowledge workers. The boom in information technology, a diverse local and immigrant workforce, and a flexible external labor market all facilitated this emphasis on rapid knowledge acquisition in both countries.

This study shows us that there is increasingly mobile view of managerial knowledge and capabilities. American firms move actively to fill their competence gaps as their organization changes structures and strategies. Firms have gotten used to being able to plug in and rotate the high impact executives in the most need areas (Bartlett Mar 2001; Lawrence and Bogumil Nov 2000; Pfeffer Spring 2001). The war for talent is relentless and only economic downturns mitigate this fierce competition for knowledge workers.

Many of these observations are in strong contrast to the view that a firm gets its competitiveness from developing its core competence over the long term. In the U.S. especially, the focus on developing company culture, extensive training and long internal careers have been pushed aside by the emphasis on speedy product development and rapid adjustments to market demands.

This paper is an extension of the research being done on the growth of on-line recruitment strategies (Flynn, McCombs et al. 1990; Bell and Sutton 1998; Boehle May 2000). However, our examination of the phenomenon indicates that firms should clearly modify their recruitment strategies as they operate in different environments. An emphasis on desired traits and skills in position advertisements might be sufficient. The explicit stating of expected performance outcomes might run counter to institutional and cultural norms in many parts of the world. It is also likely that a more balanced combination of relationship driven referrals and on-line screening would be most effective. Further studies might want to examine other parts of Asia and Europe to verify whether or not the American on-line recruitment approach is taking hold. 


\section{References}

1. $\quad$ Appleton, E. L. (1995). "Recruiting on the Internet." Datamation 41: 39-41.

2. $\quad$ Bartlett, C. (Mar 2001). "Leading people as volunteer investors." Executive Excellence 18: 16.

3. Bell, R. S. and S. W. Sutton (1998). "Building your online recruiting presence." Human Resources Professional 11: 10-14.

4. $\quad$ Bice, M. O. (1990). "Recruitment: Ensuring the Right Fit." Hospitals 64: 74.

5. Bigelow, M. M. (1999). "Recruitment online: Reinventing the process." Ohio CPA Journal 58: 30-32.

6. $\quad$ Birkett, B. (1995). "Knowledge management." Chartered Accountants Journal of New Zealand 74: 14-18.

7. $\quad$ Boehle, S. (May 2000). "Online recruiting gets sneaky.” Training 37: 66-74.

8. Bretz, R. D., Jr. and T. A. Judge (1998). "Realistic job previews: A test of the adverse self-selection hypothesis." Journal of Applied Psychology 83: 330-337.

9. Buckley, M. R., D. B. Fedor, et al. (1998). "Investigating newcomer expectations and job-related outcomes.” Journal of Applied Psychology 83: 452-461.

10. Campbell, N. (1994). "The role of Japan's top managers." Journal of General Management 20: 20-28.

11. Casper, R. E. (1985). “On-Line Recruitment.” Personnel Journal 64: 50-55.

12. Day, J. (Mar 2000). "Online job ads with a human touch." HRMagazine 45: 140-142.

13. Dean, R. A. and J. P. Wanous (1984). "Effects of Realistic Job Previews on Hiring Bank Tellers." Journal of Applied Psychology 69: 61-68.

14. Flynn, R., T. McCombs, et al. (1990). "Staffing the Self-Managing Work Team." Leadership \& Organization Development Journal 11: 26-31.

15. Freeman, L. (1999). "Some agencies learn to recruit at Internet speed." Advertising Age 70: S32-S34+.

16. Green, P. C. (1991). "Behavioral Interviewing." Executive Excellence 8: 10-11.

17. Greengard, S. (1995). "Are you well armed to screen applicants?” Personnel Journal 74: 84-95.

18. Greengard, S. (1995). "Catch the wave as HR goes online." Personnel Journal 74: 54-68.

19. Grinnell, D. J. and R. F. Kochanek (1976). "Capabilities and Role of the Contemporary Management Accountant." Ria Cost \& Management 50: 40-43.

20. Hildebrand, C. (1998). "Hiring, firing \& wiring." CIO 11(Section 2): 74-80.

21. Hoffman, P. A. (1996). "The aura of a winner." Journal of Property Management 61: 16-18+.

22. Hom, P. W., R. W. Griffeth, et al. (1998). "An exploratory investigation into theoretical mechanisms underlying realistic job previews." Personnel Psychology 51: 421-451.

23. Huff, A. (1990). Mapping Strategic Thought. New York, Wiley.

24. Jiang, J. J., G. Klein, et al. (1998). "Important behavioral skills for IS project managers: The judgments of experienced IS professionals." Project Management Journal 29: 39-43.

25. Kay, A. S. (2000). "Recruiters embrace the Internet." Informationweek: 72-80.

26. Kolb, D. G. and D. Shepherd (1997). "Concept Mapping Organizational Cultures." Journal of Management Inquiry 6(4): 282-295.

27. Lawrence, A. and W. A. Bogumil, Jr. (Nov 2000). "Foreign knowledge workers as a strategic staffing option." Academy of Management Executive 14: 71-84.

28. Lewin, R. and B. Regine (Sep/Oct 2000). "The soul at work: Human capital with a human face." Rural Telecommunications 19: 44-47.

29. Markham, K. M., J. J. Mintzes, et al. (1994). "The concept map as a research and evaluation tool:Further evidence of validity." Journal of Research in Science Teaching 31(1): 91-101.

30. Martinez, M. N. (Aug 2000). "Get job seekers to come to you." HRMagazine 45: 44-52.

31. McBain, R. (1998). "Human resources management: The changing role of the manager." Manager Update 9: 23-34.

32. Meger, B. (1996). "A critical review of competency-based systems." Human Resources Professional 9: 2225 .

33. Mercer, M. W. (1993). "Screening for the right candidates." Human Resources Professional 6: 9-13.

34. Neumann, D. F. (1988). "Using Supervisory-Based Job Analysis to Integrate and Support Human Resource Programmes." Journal of Managerial Psychology 3: 10-13.

35. Pfeffer, J. (Spring 2001). "Fighting the war for talent is hazardous to your organization's health." Organizational Dynamics 29: 248-259. 
36. Phillips, J. M. (1998). "Effects of realistic job previews on multiple organizational outcomes: A metaanalysis." Academy of Management Journal 41: 673-690.

37. Pitt, M. and K. Clarke (1999). "Competing on competence: A knowledge perspective on the management of strategic innovation." Technology Analysis \& Strategic Management 11: 301-316.

38. Rawls, J. (1974). "Recent Trends in Management Selection.” Personnel Journal 53: 104-109.

39. Roberts, K., E. E. Kossek, et al. (1998). "Managing the global workforce: Challenges and strategies." Academy of Management Executive 12: 93-106.

40. $\quad$ Robinson, D. V. (1998). "Behavioral interviewing at CIGNA.” HR Focus 75: 6.

41. Rollins, T. (1989). “A Blueprint for Salespeople Who Really Sell.” Training 26: 50-55.

42. Rosow, J. M. (1990). "New Roles for Managers.” Vital Speeches 56: 300-303.

43. Rudich, J. (Mar/Apr 2000). "Job hunting on the Web." Link - up 17: 21.

44. Simeon, R. (1999). "Evaluating domestic and international web-site strategies." Internet Research 9(4): 297-308.

45. Simonsen, P. and L. Davidson (1999). "Do your managers have the right stuff?" Workforce 78: 47-52.

46. Starcke, A. M. (1996). "Tailor interviews to predict performance." HRMagazine 41: 49-54.

47. Suszko, M. K. and J. A. Breaugh (1986). "The Effects of Realistic Job Previews on Applicant SelfSelection and Employee Turnover, Satisfaction, and Coping Ability." Journal of Management 12: 513-523.

48. Tweney, D. (1999). "Measuring Internet Success: you shouldn't rely on traffic alone." InfoWorld 21(58).

49. Urgo, M. (1997). "Deconstructing Web sites: An alternative technique for Web site evaluation and filtering." Business Information Review 14(2): 85-87.

50. Walker, J. W., W. E. Reif, et al. (1999). "Human resource leaders: Capability strengths and gaps / Comment." HR. Human Resource Planning 22: 21-32.

51. Welch, J. (1999). "British firms lag behind surfing USA.” People Management 5: 13.

52. Worledge, L. (1992). "Competencies - The Quest for the Managerial "X" Factor." Practising Manager 12: 11-14. 